\begin{tabular}{lll}
\hline Bentham open & The Open Public Health Journal \\
\hline & CrossMark & DOI: $10.2174 / 1874944501710010069$ \\
\hline
\end{tabular}

RESEARCH ARTICLE

\title{
Well-Being of Nursing Students: Role of Affect Regulation, Self- Esteem, Family Cohesion and Social Support
}

\author{
Andreja Brajsa-Zganec ${ }^{1}$, Ljiljana Kaliterna Lipovcan ${ }^{1, *}$, Danijela Ivanovic ${ }^{2}$ and Zvjezdana Prizmic \\ Larsen $^{3}$ \\ ${ }^{1}$ Ivo Pilar Institute of Social Sciences, Zagreb, Croatia \\ ${ }^{2}$ Ministry of Justice RoC, Independent Service for Victim and Witness support, Zagreb, Croatia \\ ${ }^{3}$ Washington University in St. Louis, St.Louis, Missouri, USA
}

Received: December 30, 2016

Revised: January 03, 2017

Accepted: February 03, 2017

\section{Abstract:}

\section{Background:}

Nursing is a profession often characterized with high level of stress, physical and mental demands at work, which then can bring personal and social strains in nurses' life. It is important to identify the factors, which can lead to nurses' better subjective wellbeing.

\section{Objective:}

This study explores the relationship between subjective well-being (life satisfaction, happiness) and set of personal (self-esteem, affect regulation strategies) and social variables (family cohesion, social support).

\section{Method:}

411 participants were nursing part-time students, $79 \%$ females ( $\mathrm{M}=25$ years). They reported life satisfaction, happiness, strategies used by the Measure of Affect Regulation Styles classified into 6 scales: Behavioral, Cognitive, Situation-directed, Affect-directed, Disengagement and Avoidance, Rosenberg Self-Esteem Scale, Family cohesion scale and shortened and adapted version of the Interpersonal Support Evaluation List belonging subscale, their gender, age and socioeconomic status.

\section{Results:}

Well-being variables were best predicted positively by behavioral and affect-focused strategies, social support, family cohesion and self-esteem. Both sets of personal and social variables showed similar predictive power.

\section{Conclusion:}

The findings of our study showed the importance of personal as well as social variables in predicting well-being among nursing students. Providing strong social support and good family cohesion, as well as using effective regulation strategies and having higher self-esteem would help in improving their life satisfaction and happiness.

Keywords: Life satisfaction, Happiness, Affect regulation, Self-esteem, Family cohesion, Social support.

\section{INTRODUCTION}

The nursing profession is physically and emotionally demanding and often stressful occupation. Recent study conducted in twelve European countries showed that long working hours and high burnout in hospital nurses may pose

* Address correspondence to this author at the Ivo Pilar Institute of Social Sciences, Marulicev trg 19/1, Zagreb, Croatia; Tel: +385-1-4886820; E-mail: Ljiljana.Kaliterna@pilar.hr 
safety risks for patients as well for nurses [1]. According to one definition nursing is "informed caring for the wellbeing of others" [2] and there are numerous studies on well-being and quality of life of patients suffering from all kind of diseases, but surveys on well-being of nursing staff are relatively rare. The present study was designed to contribute to this field of research by examining the relationships between subjective well-being and set of personal and social variables on the sample of nursing part-time students. The students were chosen as participants because they are preparing for a very stressful job, and it seemed appropriate to examine their well-being before they start with their professional work. When examining workers in stressful occupations there is always a potential problem of selfselection, i.e. workers who could not endure hard work conditions left the job, leaving only those who could cope with the workplaces [3].

Subjective Well-Being (SWB) is a multidimensional construct defined as people's overall evaluations of their lives and their emotional experiences [4]. It includes cognitive and affective components, the cognitive component referring to subjective evaluation of life circumstances (life satisfaction), and affective component referring to the balance of positive and negative affects experienced over time (happiness). Studies have found that both components have distinct correlates and it is recommended to assess these components separately in research of well-being [5 - 7]. Research shows that higher SWB is associated with better functioning in various life domains such as health, longevity, income, productivity, individual and social behavior [8 - 10]. As determinants of well-being, the various socio-demographic, personal, social and societal characteristics have been examined $[4,11,12]$. In the present study we examined two sets of personal and social variables in relation to SWB. Personal variables included self-esteem and affected regulation strategies and social variables including family cohesion and social support.

Among the personal variables, self-esteem, defined as an overall evaluation of one's worthiness [13] was found to be an important factor related to people's SWB [14 - 18]. High self-esteem was found to lead to greater happiness, while low self-esteem can lead to depression under some circumstances [14].

Affect regulation may play an important role in defining people's SWB. It is defined as the management of affective states in order to maintain or change (enhance or suppress) the intensity of effect [19]. Specific behaviors and actions are used to maintain or increase positive effect and to decrease negative one. Some regulation strategies, such as reappraisal, have greater benefits for affective functioning, social interactions, and well-being, than others, for example suppression [20]. Engagement strategies were found to be related to higher levels of cheerfulness [21]. Similarly, more frequent use of cognitive strategies, and less frequent use of avoidance strategies were related to higher well-being [22 24]. Emotional regulation is thought to be important for well-being, because emotions serve communicative and social functions, coordinate social encounters and help in social interaction [25, 26]. Growing body of research demonstrates the use of effective strategies and the ability of experiencing positive affect in stressful situation or aversive negative feelings may help to replenish personal resources and mange to better cope with it [19, 27]. Fredrickson and colleagues proposed the broaden-and-build theory of positive emotions which provides a comprehensive theoretical framework that explain how positive emotions may lead to better individual functioning in everyday life [27, 28]. The theory posits that, even though positive emotions are inherently fleeting and short in duration, they can also have more long-lasting benefits by building people's personal resources. The existing scientific evidence demonstrated that positive emotions broaden thought-action repertoires, which, in turn, promotes behavioural flexibility, helps to recover from aversive experiences and builds personal resources. Over time, these positive experiences can aggregate into consequential resources, as an upward spiral that has the potential to transform peoples' lives [27 - 29].

One of the most consistent predictors of SWB is the quality of social relationships $[30-33,16]$. People with rich and satisfying relationship, experiencing social support, report feeling happy and satisfied with their lives [34, 35]. Social support was, besides income and health, found to be one of the three most important factors explaining differences in SWB among countries, and also among regions [36, 37]. Social support can be defined as a social network providing emotional, informational and instrumental resources [33]. There are two theoretical models in which social support can affect SWB: as a general positive effect of support (main effect model) or as a process of support protecting persons from potentially harmful effects of stressful events (buffering model) [38]. Previous research showed evidence for both models of social support effects [39 - 41], each model pointing to a different process through which social support may affect SWB depending on the measures of social support (perceived availability of interpersonal resources or person's degree of integration in a social network) [38]. Research findings suggest that subjective evaluations of social support are strongly related to SWB - individuals who have satisfying relationships can obtain support when they need it, or the expectation of being able to rely on someone when needed is comforting, and as a result, contributes to people's SWB [30]. 
The most important source of social support is family, as a primary social group. One of the dimensions of family functioning is family cohesion defined as the emotional bonding among family members and the degree of personal autonomy within the family [42]. Family cohesion was found to be strongly related to well-being of young people [43]. Similar findings were reported in Croatian study where family cohesion and parental support represented protective factors which directly influenced adolescent's well-being [16].

\begin{abstract}
Aims
The present study was aimed to examine the relationships between subjective well-being (life satisfaction, happiness) and set of personal (self-esteem, affect regulation strategies) and social variables (family cohesion, social support) on the sample of nursing part-time students. Based on prior research, we hypothesized that both personal and social variables would predict well-being. Furthermore, we wanted to explore if those relationships would be different for cognitive (life satisfaction) and affective (happiness) components of well-being. Finally, we aimed to determine which set of variables, personal or social, would have stronger predictive power for cognitive or affective measure of well-being, after controlling for the socio-demographic variables (gender, age and socioeconomic status).
\end{abstract}

\title{
MATERIALS AND METHODS
}

\section{Participants and Procedures}

Participants were 411 nursing students from one of the Croatian Universities. They were enrolled at second-year classes, out of a three-year study. The sample comprised of 79.6\% females with age range from 19 to 54 years (Median=22; $\mathrm{M}=24.7, \mathrm{SD}=6.74$ ). Participants were part-time students having regular classes during weekends, $45 \%$ of them were working. Most of the participants rated their socioeconomic status as average (87\%), $8 \%$ of them rated it as low, and $5 \%$ of the participants rated socioeconomic status as high. By marriage status $77 \%$ were not married, $20 \%$ were married, $2 \%$ divorced, and $1 \%$ widowed.

Participants completed a battery of questionnaires during group sessions and they were guaranteed confidentiality. The study was conducted in spring 2015.

\section{Instruments}

Subjective Well-Being. The Life satisfaction scale and the Happiness scale were used to measured cognitive and affective components of SWB, respectively.

The Life satisfaction scale consists of a single-item question "All things considered, how satisfied are you with your life as a whole nowadays?" which participants rated on the 11-point scale ( 0 as "extremely dissatisfied" to 10 as "extremely satisfied"). The one-item measure was acquired from European Social Survey Well-being module [44]. The Happiness Scale is a single-item question "In general, how happy do you feel?" which participants rated on the 11-point scale (0 as "extremely unhappy" to 10 as "extremely happy"). The measure is adapted from the Fordyce Happiness Scale [45]. Higher scores on both scales indicate higher levels of life satisfaction and happiness.

Affect Regulation. Participant's affect regulation strategies were measured using the Measure of Affect Regulation Styles (MARS) [19]. In this study the shortened form was used, which consists of six items of affect regulation strategies [22]. Each item was described by listing few examples of specific behaviors: Behavioral strategies (going out with friends, socializing, doing something fun, laughing), Cognitive strategies (thinking on things that are going well, being grateful, putting things in perspective), Situation-focus (planning for the future, avoiding the problem in the future, finishing things, reinterpreting), Affect-focus strategies (talking about feelings, expressing feelings, asking for advice, writing about feelings, understanding feelings), Disengagement (letting things wait, doing nothing) and Avoidance (suppressing feelings, wanting to be alone, thinking to distract oneself, avoiding the situation). Participants assessed how frequently they used certain affective regulation strategies to regulate their negative feelings in everyday life. Responses are made on a 7-point ( 0 as "not at all" to 6 as "almost always") Likert-type scale.

Self-Esteem. The Rosenberg Self-Esteem Scale measures global self-esteem and overall feeling of self-worth [13]. The scale consists of ten items (e.g., "I feel that I have a number of good qualities") that are rated on a 4-point scale (1 as "strongly disagree" to 4 as "strongly agree"). Average score was calculated with higher score indicating higher level of self-esteem. In this study, reliability of the scale was Cronbach's alpha=.74. Previous research with the Rosenberg Self-Esteem Scale in Croatia that used different samples showed acceptable psychometric characteristics of the scale, with Cronbach's alpha ranging from .84 to .87 [46 - 48]. 
Family Cohesion. The family cohesion subscale of the Colorado self-report measure of family functioning [42] is a five-item scale used to assess the emotional bonding family members have with one another. Items (e.g., "Family members really help and support one another") are rated on a 4-point scale (1 as "not at all" to 4 as "yes, completely"). Higher cohesion scores indicate higher family cohesion. In this study, reliability of the scale was Cronbach's alpha=.86. The scale has demonstrated good reliability in different samples in Croatia in our previous research, with Cronbach's alpha ranging from .72 to $.82[16,46]$.

Social Support. The Interpersonal Support Evaluation List (ISEL) [34] is a global measure of perceived social support across four domains (belonging, self-esteem, appraisal, and tangible support). In this study, shortened and adapted version of the ISEL belonging subscale with 9 items was used [49]. Participants assessed the agreement with each statement on a 4-point scale (1 as "strongly disagree" to 4 as "strongly agree"). Average score was calculated with higher score indicating higher social support. In this study, reliability for the subscale was Cronbach's alpha=.77. Previous research in Croatia showed acceptable psychometric characteristics of the perceived social support belonging subscale (Cronbach's alpha=.71) [49].

Sociodemographic variables. Participants' age, gender, and socioeconomic status were obtained.

\section{Data Analyses}

Hierarchical regression analyses were employed to evaluate the relationship between each of the subjective wellbeing measures (Life satisfaction, Happiness) with two sets of predictors: personal variables (Self-esteem, six Affect regulation strategies) and social variables (Family cohesion, Social support), while controlling for the impact of a set of socio-demographic variables (gender, age and socioeconomic status). This ensured that the observed effect of the sets of the personal and the social variables on subjective well-being was independent of the effects of controlled variables. Also, descriptive statistics of measured variables as well as the correlation analyses between subjective well-being measures, personal and social variables were performed for better understanding of obtained results. Before conducting regression analyses we tested whether the data met the assumption of no multicollinearity by using the Variance inflation factor (VIF), which is a measure of how much the variance of the estimated regression coefficient is inflated by the existence of correlation among the predictor variables in the model. A VIF greater of 10 means, that there are signs of multicollinearity [50]. The VIF values for our data ranged from VIF=1.06 for Self-esteem to VIF $=1.90$ for Cognitive strategies, indicating that the data met the assumption of no multicollinearity. All analyses were performed using Statistical Package for the Social Sciences (SPSS) version 22.

\section{RESULTS}

Mean scores, standard deviations (SD), and theoretical range in subjective well-being measures (Life satisfaction, Happiness), personal variables (Self-esteem, six Affective regulation strategies) and social variables (Family cohesion, Social support) obtained on the sample of nursing students are reported in Table 1.

Table 1. Descriptive statistics of subjective well-being, affective regulation, self-esteem, family cohesion and social support variables.

\begin{tabular}{|c|c|c|}
\hline & Mean (SD) & Theoretical Range \\
\hline Subjective Well-Being Measures & & $0-10$ \\
\hline Life Satisfaction & $7.7(1.97)$ & $0-10$ \\
\hline Happiness & $7.4(1.73)$ & $1-4$ \\
\hline Personal Variables & & \\
\hline Self-Esteem & $3.0(0.49)$ & $0-6$ \\
\hline Affect Regulation Strategies & & $0-6$ \\
\hline Behavioral & $5.0(1.42)$ & $0-6$ \\
\hline Cognitive & $4.9(1.35)$ & $0-6$ \\
\hline Situation-Focus & $5.0(1.26)$ & $0-6$ \\
\hline Affect-Focus & $5.0(1.53)$ & $0-6$ \\
\hline Disengagement & $2.7(1.37)$ & $3.2(1.60)$ \\
\hline Avoidance & & $1-4$ \\
\hline Social Variables & $3.2(0.53)$ & $1-4$ \\
\hline Family Cohesion & $3.1(0.43)$ & \\
\hline Social Support & & \\
\hline
\end{tabular}


Inter-correlation analyses between subjective well-being variables (Happiness, Life Satisfaction), six Affect regulation strategies, Self-esteem, Family cohesion and Social support revealed a number of significant associations that are presented in Table 2. Subjective well-being measures were significantly related to all measured variables showing weak to moderate relationships with exception of the Disengagement strategies. In general, happy participants and with better life satisfaction reported using more Behavioral, Cognitive, Situation- and Affect-focus strategies and less Disengagement strategies, as well as higher self-esteem, better family cohesion and stronger social support than their counterparts.

Table 2. Inter-correlations between subjective well-being, affect regulation strategies, self-esteem, family cohesion and social support variables.

\begin{tabular}{|c|c|c|c|c|c|c|c|c|c|c|}
\hline & $\mathbf{1}$ & $\mathbf{2}$ & $\mathbf{3}$ & $\mathbf{4}$ & $\mathbf{5}$ & $\mathbf{6}$ & $\mathbf{7}$ & $\mathbf{8}$ & $\mathbf{9}$ & $\mathbf{1 0}$ \\
\hline 1. Happiness & & & & & & & & & & \\
\hline 2. Life Satisfaction & $.72^{* *}$ & & & & & & & & & \\
\hline 3. Behavioral & $.39^{* *}$ & $.37^{* *}$ & & & & & & & & \\
\hline 4. Cognitive & $.35^{* *}$ & $.31^{* *}$ & $.56^{* *}$ & & & & & & & \\
\hline 5. Situation-focus & $.30^{* *}$ & $.27^{* *}$ & $.39^{* *}$ & $.57^{* *}$ & & & & & & \\
\hline 6. Affect-focus & $.27^{* *}$ & $.32^{* *}$ & $.24^{* *}$ & $.29^{* *}$ & $.29^{* *}$ & & & & & \\
\hline 7. Disengagement & -.10 & -.07 & $-.10^{*}$ & $-.23^{* *}$ & $-.32^{* *}$ & $-.19^{* *}$ & & & & \\
\hline 8. Avoidance & $-.16^{* *}$ & $-.15^{* *}$ & $-.13^{*}$ & $-.24^{* *}$ & $-.24^{* *}$ & $-.30^{* *}$ & $.50^{* *}$ & & & \\
\hline 9. Self-Esteem & $.18^{* *}$ & $.23^{* *}$ & .05 & .04 & .08 & $.11^{*}$ & -.06 & $-.14^{* *}$ & & \\
\hline 10. Family Cohesion & $.31^{* *}$ & $.36^{* *}$ & $.17^{* *}$ & $.13^{*}$ & $.11^{*}$ & $.11^{*}$ & -.03 & .06 & .07 & \\
\hline 11. Social Support & $.43^{* *}$ & $.38^{* *}$ & $.35^{* *}$ & $.22^{* *}$ & $.18^{* *}$ & $.18^{* *}$ & -.06 & $-.14^{* *}$ & $.14^{* *}$ & $.26^{* *}$ \\
\hline
\end{tabular}

Notes: $* * \mathrm{p}<.01, * \mathrm{p}<.05$; The numbers from 1-11 in the first raw correspond to the numbers of the variables in the first column.

To further explore the associations between well-being measures (Life satisfaction, Happiness) with personal (Selfesteem, six Affect regulation strategies) and social variables (Family cohesion, Social support) hierarchical regression analyses were conducted separately on each of the well-being variable with the socio-demographic variables (age, gender, socioeconomic status) as covariates. We run two models to explore which set of predictors, personal or social, were stronger in predicting the well-being variables with the covariates entered at the first step. Both models produced almost identical R square changes and they were significant to the same extent, which pointed out that both sets of predictors were similar in magnitude in predicting well-being variables. Thus, we presented the results of one of the model, with set of personal variables, i.e., Self-esteem, six Affect regulation strategies entered at the second step, and social variables, i.e., Family cohesion and Social support were entered at the third step and we focused our results on the final full model. Table 3 summarizes the results of the hierarchical regression analyses which contains standardized coefficient betas $(\beta)$, R square changes associated with each of the steps ( $\mathrm{R}^{2}$ change), adjusted $\mathrm{R}$ square for each step (adjusted $\mathrm{R}^{2}$ ) and multiple $\mathrm{R}$ of the final model for each well-being variables.

Table 3. Summary of hierarchical regression analyses for personal (self-esteem, six affect regulation strategies) and social (family cohesion, social support) variables predicting life satisfaction and happiness.

\begin{tabular}{|c|c|c|c|c|c|c|}
\hline & \multicolumn{3}{|c|}{$\begin{array}{c}\text { Life Satisfaction } \\
\text { Standardized Betas }(\beta) \\
\end{array}$} & \multicolumn{3}{|c|}{$\begin{array}{c}\text { Happiness } \\
\text { Standardized Betas }(\beta) \\
\end{array}$} \\
\hline & Step 1 & Step 2 & Step 3 & Step 1 & Step 2 & Step 3 \\
\hline \multicolumn{7}{|c|}{ Sociodemographic Variables } \\
\hline Gender & .01 & -.03 & -.05 & .01 & -.02 & -.03 \\
\hline Age & $-.14 * *$ & $-.12 * *$ & $-.09 *$ & $-.12 *$ & $-.10 *$ & -.06 \\
\hline Socioeconomic Status & $.27 * *$ & $.17 * *$ & $.18^{* *}$ & $.18^{* *}$ & .08 & .08 \\
\hline \multicolumn{7}{|l|}{ Personal Variables } \\
\hline Self-Esteem & & $.15^{* *}$ & $.13 * *$ & & $.12 * *$ & $.09 *$ \\
\hline Behavioral Strategies & & $.23 * *$ & $.15^{* *}$ & & $.24 * *$ & $.14 * *$ \\
\hline Cognitive Strategies & & .06 & .05 & & .11 & .10 \\
\hline Situation-Focus & & .08 & .06 & & .09 & .07 \\
\hline Affect-Focus & & $.18^{* *}$ & $.16^{* *}$ & & $.12 * *$ & $.10^{*}$ \\
\hline Disengagement & & .06 & .03 & & .04 & .01 \\
\hline Avoidance & & -.06 & -.02 & & -.06 & -.02 \\
\hline Social Variables & & & & & & \\
\hline
\end{tabular}


(Table $\square$ ) contd......

\begin{tabular}{|c|c|c|c|c|c|c|}
\hline & \multicolumn{3}{|c|}{$\begin{array}{c}\text { Life Satisfaction } \\
\text { Standardized Betas }(\beta)\end{array}$} & \multicolumn{3}{|c|}{$\begin{array}{c}\text { Happiness } \\
\text { Standardized Betas }(\beta)\end{array}$} \\
\hline & Step 1 & Step 2 & Step 3 & Step 1 & Step 2 & Step 3 \\
\hline Family Cohesion & & & $.24 * *$ & & & $.18 * *$ \\
\hline Social Support & & & $.17 * *$ & & & $.25^{* *}$ \\
\hline $\mathrm{R}^{2}$ Change & $.09 * *$ & $.19 * *$ & $.10 * *$ & $.04 * *$ & $.20 * *$ & $.10 * *$ \\
\hline Adjusted $\mathrm{R}^{2}$ & $.08 * *$ & $.26^{* *}$ & $.36^{* *}$ & $.04 * *$ & $.22 * *$ & $.32 * *$ \\
\hline Multiple R & $.30 * *$ & $.53 * *$ & $.61 * *$ & $.21 * *$ & $.49 * *$ & $.58 * *$ \\
\hline
\end{tabular}

Notes: ${ }^{* *} \mathrm{p}<.01,{ }^{*} \mathrm{p}<.05$; Gender is coded into $1=$ man and $2=$ women; A pairwise treatment of missing data was used which can produce different significance level of the same value of standardized beta.

The hierarchical regression analysis with Life satisfaction showed that multiple $\mathrm{R}$ for the final model was 0.61 $(\mathrm{p}<.01)$. Overall, all variables in the model explained $36 \%$ of the variance in Life satisfaction. Based on R square change, set of the personal variables (Self-esteem and six Affect regulation strategies) predicted 19\% of the variance in the Life satisfaction over and above the set of socio-demographic variables (gender, age, socioeconomic status) which alone accounted for $9 \%$ of the variance in Life satisfaction. In the third step, set of the social variables (Family cohesion, Social support) predicted $10 \%$ of the variance in the Life satisfaction over and above the socio-demographic and personal variables. As mentioned before, when we reversed the set of variables entered in the model, i.e., social variables at the second and personal variables at the third step, $R$ square change stayed the same, 0.19 and 0.10 respectively. Regardless what set of variables were entered at the second or third steps, results showed that both set of predictors had similar power in predicting Life satisfaction. In other words, the contribution to the explanation of the variance in Life satisfaction was similar for both sets of the personal variables and set of the social variables. Also, it was larger for both sets than for the socio-demographic variables. People with stronger family cohesion and social support, higher self-esteem, and use of behavioral and affect-focus strategies reported better life satisfaction.

Similar findings were obtained when predicting Happiness. Multiple R for the final model was $0.58(\mathrm{p}<.01)$ and all variables in the model explained $32 \%$ of the variance in Happiness. Based on R square change, contribution of sociodemographic variables was quite small, $4 \%$, while set of the personal variables (Self-esteem and six Affect regulation strategies) predicted $20 \%$ and set of social variables $10 \%$ of the variance in the Happiness. When we reversed the set of variables entered in the model, i.e., social variables at the second and personal variables at the third step, $\mathrm{R}$ square change stayed almost the same, 0.21 and 0.09 respectively, which was the similar finding to Life satisfaction results. In other words, contribution to the explanation of the variance in Happiness was similar for both sets of the personal variables and set of the social variables. However, in the final model the significance of socio-demographic variables in predicting Happiness disappeared. People with strong social support, family cohesion, and higher self-esteem and who reported using more behavioral and affect-focus strategies reported to be happier.

\section{DISCUSSION}

The present study examined relationships between well-being and sets of personal and social variables in a sample of nursing part-time students $(\mathrm{N}=411)$. Well-being was measured as cognitive (life satisfaction) and affective (happiness) components, personal variables included self-esteem and six affect regulation strategies, while social variables included perceived social support and family cohesion.

Nursing students participating in this study reported relatively high levels of subjective well-being, measured by both components (life satisfaction $\mathrm{M}=7.7$; happiness $\mathrm{M}=7.4$ ). These results were higher in comparison to levels of wellbeing measures obtained at the same time (spring 2015) on the nationally representative sample of Croatian citizens $(N=1000)$, where average level of life satisfaction was $M=6.6$, and of happiness was $M=7.0$ [51]. Similar results of higher well-being in care giving professionals than in general population were obtained also in our previous research conducted in 2003 [52]. One of the explanations of such findings might be that people working jobs where they care for other people are aware of stressful job circumstances and are satisfied to be able to cope with it, which leads to higher well-being [53]. Another explanation of the fact that nursing students reported higher SWB than average population might be their younger age, better education level and the fact that $45 \%$ of them were employed.

Further, we examined the predictors of cognitive (life satisfaction) and affective (happiness) measures of SWB, while controlling for effects of age, gender and socioeconomic status. Two groups of predictors were employed; one referring to the group of personal characteristics (self-esteem and frequency of use of six affect regulation strategies) and another on social relations (social support and family cohesion). Three sets of variables - socio-demographic, 
personal and social characteristics explained together $36 \%$ of variance in life satisfaction and $32 \%$ of variance in happiness.

Even after controlling for socio-demographic characteristics, age and socioeconomic status were still significant predictors of life satisfaction, but not of happiness. Younger students and those with higher socioeconomic status reported higher life satisfaction. Similar results were obtained also in earlier research of Croatian population [54, 55]. As a transition country undergoing slow recovery from recent economic recession, Croatia is among these countries where higher socioeconomic status and younger age are associated with higher SWB. The finding that "objective" circumstances (age and socioeconomic status) showed greater impact on life satisfaction than on happiness, is in line with research showing that cognitive component of SWB, such is life satisfaction is more sensitive to material conditions, than happiness and other affective states [56 - 58].

Among the set of personal variables, self-esteem and frequent use of behavioral and affect-focus strategies predicted both, life satisfaction and happiness. Students with higher levels of self-esteem reported to be more satisfied with their lives and to be happier. However, self-esteem was slightly better predictor of cognitive then affective component of SWB. One explanation is that both constructs are cognitive in nature, self-esteem as personal judgment of worthiness and life satisfaction as personal judgment of quality of life [18, 59].

Frequent use of behavioral and affect-focus strategies to regulate negative moods were associated with better life satisfaction and being happier. These strategies comprise behaviors or actions that involve active ways to regulate negative mood, such are going out or socializing, as a part of behavioral strategies, or talking about feeling and asking for advice, as a part of affect-focus strategies. These two strategies were also found to be the most frequently used among nursing students (Table 1). Some other research also showed that the most frequently used strategies were the active, engagement type of strategies [21, 60].

Some researchers emphasized that the effectiveness of strategies depend on their focus on coping with and reducing the aversive effects of negative emotions $[19,61]$ while others emphasized the importance of strategies focused on maintaining positive emotions [62]. Both of the approaches, through the different pathways, describe enhancing wellbeing. According to the broaden-and-build theory of positive emotions there is a bidirectional association between positive affect and self-regulation resources. As Fredrickson and colleagues have proposed in their theory, positive emotions broaden the individual's attentional focus and behavioral repertoire and, as a consequence, build social, intellectual and physical resources such as social support, broad-minded coping, and interpersonal trust [27 - 29]. Thus in the context of aversive situation in one's area of life, positive affect may strengthen self-regulation resources to prevent it for spilling over into other areas of life [63].

Satisfying family cohesion and stronger social support predicted both life satisfaction and happiness. The findings are in accordance with previous research showing that social relationships are probably the most important for high SWB [14 - 17, 30 - 34, 64, 65]. Within this set of variables used, family cohesion was the strongest predictor of life satisfaction, while social support was the strongest predictor of happiness. Previous research also found stronger associations of social support with happiness than with life satisfaction $[30,56]$. Better perceived social support and satisfying family cohesion are important for harmonious interpersonal relationships which help individuals maintain high well-being and protect them in stressful situation. As a profession working under high pressure, nurses are exposed to stressful situations and therefore it is of great importance to improve their well-being [66].

In short, the findings of our study, showed the importance of personal as well as social variables in predicting wellbeing among the nursing students. Considerable attention in recent literature has been focused on helping students in coping with stress and burnout, especially among those students who are preparing for one of the caring profession [67 69]. Most studies on different intervention for reducing students' stress levels have been conducted with nursing students, while few of them with social work, psychology and family therapy students [67]. Evidence shows that among nursing students, supervision, the workshops and seminars oriented in helping them to learn the specific techniques and strategies for coping with the stress are helpful in reducing the burnout [69]. Beside intervention to reduce the stress, another approach has been focused on interventions designed to increase subjective well-being of the person [4]. Techniques to increase persons' happiness can be designed as simply encouraging intentional positive activities, either social-behavioral in nature (such as expressing gratitude or practicing kindness), or reflective and cognitive (such as savoring the moments or thinking optimistically on the future) $[4,70]$.

Practical implications of our study may be directed to the later line of research, in encouraging the interventions with the aim to enhance different components of subjective well-being. These interventions can be implemented at 
different levels from individual student, groups of students, teachers to educational institutions. Our results pointed out the ways in which nursing students' subjective well-being can be improved by considering the factors that affects their happiness and life satisfaction. The emphasize should be put in providing strong social support and good family cohesion, as well as maintain higher levels of self-esteem and using active strategies to regulate negative feelings in everyday life.

There are several limitations of this study. The correlational nature of this research does not allow any causal interpretation of the relationships between well-being and examined variables. The sample consisted of students so that results cannot be generalized. It would be interesting to contrast these results with other part-time students, in order to know if the conclusions obtained are associated with age or work status, or with the chosen studies. Additional concerns can be raised about the psychometric properties of single-item life satisfaction and happiness measures which were used instead of multi-item scales, such as the Satisfaction with Life Scale [71] and Positive and Negative Affect Schedule scale [72]. Published studies do provide support for the validity of single-item measure of life satisfaction [73, 74] though longer scales may provide multidimensional assessment or higher internal consistencies. Future research should include longitudinal approach, with inclusion of objective measures, for example the level of stress at work, peer reports of ways to cope with negative feelings, as well as the specific measures of positive and negative emotions for measuring affective component of well-being.

\section{CONCLUSION}

The findings of our study showed the importance of personal as well as social variables in predicting well-being among nursing students. Providing strong social support and good family cohesion, as well as using effective regulation strategies and having higher self-esteem would help in improving their life satisfaction and happiness.

\section{ETHICS APPROVAL AND CONSENT TO PARTICIPATE}

The project was approved by the Ethical Committee of the Ivo Pilar Institute of Social Sciences, Zagreb, Croatia.

\section{HUMAN AND ANIMAL RIGHTS}

No Animals/Humans were used for studies that are base of this research.

\section{CONFLICT OF INTEREST}

The authors confirm that this article content has no conflict of interest.

\section{ACKNOWLEDGEMENTS}

We thank the interviewers and participants for their cooperation during the survey.

\section{REFERENCES}

[1] DallOra C, Griffiths P, Ball J, Simon M, Aiken LH. Association of $12 \mathrm{~h}$ shifts and nurses job satisfaction, burnout and intention to leave: findings from a cross-sectional study of 12 European countries. BMJ Open 2015; 5(9): e008331. [http://dx.doi.org/10.1136/bmjopen-2015-008331] [PMID: 26359284]

[2] Swanson KM. Nursing as informed caring for the well-being of others. Image J Nurs Sch 1993; 25(4): $352-7$. [http://dx.doi.org/10.1111/j.1547-5069.1993.tb00271.x] [PMID: 8288305]

[3] Knutsson A, Akerstedt T. The healthy-worker effect: self-selection among Swedish shift workers. Work Stress 1992; 6: 163-7. [http://dx.doi.org/10.1080/02678379208260350]

[4] Diener E, Heintzelman SJ, Kushlev K, et al. Findings all psychologists should know from the new science on subjective well-being. Can Psychol, Advance online publication 2016. [http://dx.doi.org/10.1037/cap0000063]

[5] Arthaud-Day ML, Rode JC, Mooney CH, Near JP. The subjective well-being construct: a test of its convergent, discriminant, and factorial validity. Soc Indic Res 2005; 74: 445-76. [http://dx.doi.org/10.1007/s11205-004-8209-6]

[6] Proctor C. Encyclopedia of quality of life and well-being research. In: Michalos A, Ed. Springer. 2014; pp. 6437-41.

[7] Schimmack U. The Structure of Subjective Well-being. In: Eid M, Larsen RJ, Eds. The Science of Subjective Well-Being. New York: The Guilford Press 2008; pp. 97-123.

[8] De Neve J, Diener E, Tay L, Xuereb C. The objective benefits of subjective well-being. London, England: CEP discussion paper no. 1236. Centre for economic performance. 2013. [http://cep.lse.ac.uk/pubs/download/dp1236.pdf] 
[9] Diener E, Chan MY. Happy people live longer: subjective well-being contributes to health and longevity. Appl Psychol HWB 2011; 3: 1-43.

[10] Diener E. The remarkable changes in the science of subjective well-being. Perspect Psychol Sci 2013; 8(6): 663-6. [http://dx.doi.org/10.1177/1745691613507583] [PMID: 26173230]

[11] Dolan P, Peasgood T, White MP. Do we really know what makes us happy? A review of the economic literature on the factors associated with subjective well-being. J Econ Psychol 2008; 29: 94-122. [http://dx.doi.org/10.1016/j.joep.2007.09.001]

[12] Lyubomirsky S, King L, Diener E. The benefits of frequent positive affect: does happiness lead to success? Psychol Bull 2005; 131(6): $803-55$. [http://dx.doi.org/10.1037/0033-2909.131.6.803] [PMID: 16351326]

[13] Rosenberg M. Self-concept from middle childhood through adolescence. In: Suls J, Greenwald AG, Eds. Psychological perspectives on the self. New York: Hillsdale, Erlbaum 1986; Vol. 3.

[14] Baumeister RF, Campbell JD, Krueger JI, Vohs KD. Does high self-esteem cause better performance, interpersonal success, happiness, or healthier lifestyles? Psychol Sci Public Interest 2003; 4(1): 1-44. [http://dx.doi.org/10.1111/1529-1006.01431] [PMID: 26151640]

[15] Rosenberg M, Schooler C, Schoenbach C, Rosenberg F. Global self-esteem and specific self-esteem: different concepts, different outcomes. Am Sociol Rev 1995; 60(1): 141-56. [http://dx.doi.org/10.2307/2096350]

[16] Raboteg-Saric Z, Brajsa-Zganec A, Sakic M. Life Satisfaction in Adolescents: The Effects of Perceived Family Economic Status, Self-Esteem and Quality of Family and Peer Relationships. Drus Istraz 2009; 18(101): 547-64.

[17] Schimmack U, Diener E. Predictive validity of explicit and implicit self-esteem for subjective well-being. J Res Pers 2003; 37: 100-6. [http://dx.doi.org/10.1016/S0092-6566(02)00532-9]

[18] Lyubomirsky S, Tkach C, Di Matteo MR. What are the differences between happiness and self-esteem? Soc Indic Res 2006; 78: 363-404. [http://dx.doi.org/10.1007/s11205-005-0213-y]

[19] Larsen RJ, Prizmic Z. Affect regulation. In: Baumeister R, Vohs K, Eds. Handbook of self-regulation research. New York: Guilford 2004; pp. $40-60$.

[20] Gross JJ. Emotion regulation: Current status and future prospects. Psychol Inq 2015; 26: 1-26. [http://dx.doi.org/10.1080/1047840X.2014.940781]

[21] Totterdell P, Parkinson B. Classifying affect-regulation strategies. Cogn Emotion 1999; 13: 277-303. [http://dx.doi.org/10.1080/026999399379285]

[22] Prizmic Z, Larsen R. Life satisfaction and affect regulation strategies. In: Book of abstracts of the 16th European Conference on Personality, July 10-14; Trieste, Italy. 2012; p. 197.

[23] Repo V. Affect regulation strategies and their associations with subjective well-being: An international comparative survey. [master's thesis] University of Tampere, 2011. [cited 2016 Oct 6] Available from: https://tampub.uta.fi/bitstream/handle/10024/82257/gradu04815.pdf? sequence $=1$

[24] Prizmić Z. Kaliterna Lipovčan Lj, Franc R. What to do and not to do to be happy and satisfied? - Affect regulation strategies and subjective well-being in a representative sample of Croatia. In: Freire T, Ed. Understanding Positive Life Research and Practice on Positive Psychology. Lisboa: Climepsi 2009; pp. 215-30.

[25] Lopes PN, Brackett MA, Nezlek JB, Schütz A, Sellin I, Salovey P. Emotional intelligence and social interaction. Pers Soc Psychol Bull 2004; 30(8): 1018-34. [http://dx.doi.org/10.1177/0146167204264762] [PMID: 15257786]

[26] Paez D, Seguel AM, Martinez-Sanchez F. Incremental validity of alexithymia, emotional coping and humor style on happiness and psychological well-being. J Happiness Stud 2013; 14: 1621-37. [http://dx.doi.org/10.1007/s10902-012-9400-0]

[27] Fredrickson BL. The role of positive emotions in positive psychology. The broaden-and-build theory of positive emotions. Am Psychol 2001; 56(3): 218-26

[http://dx.doi.org/10.1037/0003-066X.56.3.218] [PMID: 11315248]

[28] Fredrickson BL, Joiner T. Positive emotions trigger upward spirals toward emotional well-being. Psychol Sci 2002; 13(2): 172-5. [http://dx.doi.org/10.1111/1467-9280.00431] [PMID: 11934003]

[29] Garland EL, Fredrickson B, Kring AM, Johnson DP, Meyer PS, Penn DL. Upward spirals of positive emotions counter downward spirals of negativity: insights from the broaden-and-build theory and affective neuroscience on the treatment of emotion dysfunctions and deficits in psychopathology. Clin Psychol Rev 2010; 30(7): 849-64. [http://dx.doi.org/10.1016/j.cpr.2010.03.002] [PMID: 20363063]

[30] Siedlecki KL, Salthouse TA, Oishi S, Jeswani S. The relationship between social support and subjective well-being across age. Soc Indic Res 2014; 117(2): 561-76.

[http://dx.doi.org/10.1007/s11205-013-0361-4] [PMID: 25045200] 
[31] Bradburn NM. The structure of psychological well-being. Chicago: Aldine 1969.

[32] Lincoln KD. Social relationships and health among minority older adults. In: Whitfield KE, Baker TA, Eds. Handbook of minority aging Publisher. Springer 2014; pp. 25-46.

[33] Cohen S. Social relationships and health. Am Psychol 2004; 59(8): 676-84. [http://dx.doi.org/10.1037/0003-066X.59.8.676] [PMID: 15554821]

[34] Diener E, Seligman ME. Very happy people. Psychol Sci 2002; 13(1): 81-4. [http://dx.doi.org/10.1111/1467-9280.00415] [PMID: 11894851]

[35] Diener E, Oishi S. The nonobvious social psychology of happiness. Psychol Inq 2005; 16(4): 162-7. [http://dx.doi.org/10.1207/s15327965pli1604_04]

[36] Helliwell JF, Layard R, Sachs J, Eds. World Happiness Report 2015. New York: Sustainable Development Solutions Network 2016.

[37] Brezzi M, Ramirez MD. Building subjective well-being indicators at the subnational level: A preliminary assessment in OECD regions, OECD Regional Development Working Papers, 2016/03. Paris: OECD Publishing 2016.

[38] Cohen S, Wills TA. Stress, social support, and the buffering hypothesis. Psychol Bull 1985; 98(2): $310-57$. [http://dx.doi.org/10.1037/0033-2909.98.2.310] [PMID: 3901065]

[39] Barrera M. Models of social support and life stress; Beyond the buffering hypothesis. In: Cohen LH, Ed. Life events and psychological functioning. Newbury Park: Sage 1988; pp. 211-36.

[40] Cohen S, Hoberman HM. Positive events and social supports as buffers of life change stress. J Appl Soc Psychol 1983; 13 : 99-125. [http://dx.doi.org/10.1111/j.1559-1816.1983.tb02325.x]

[41] Kessler RC, Kendler KS, Heath A, Neale MC, Eaves LJ. Social support, depressed mood, and adjustment to stress: a genetic epidemiologic investigation. J Pers Soc Psychol 1992; 62(2): 257-72. [http://dx.doi.org/10.1037/0022-3514.62.2.257] [PMID: 1556658]

[42] Bloom BL. A factor analysis of self-report measures of family functioning. Fam Process 1985; 24(2): $225-39$. [http://dx.doi.org/10.1111/j.1545-5300.1985.00225.x] [PMID: 4018243]

[43] Headey B, Wearing A. Understanding Happiness: A theory of subjective well-being. Melbourne: Longman Cheshire 1992.

[44] Huppert F, Marks N, Clark A, et al. Measuring well-being across Europe: Description of the ESS Well-being Module and preliminary findings. Soc Indic Res 2009; 91: 301-15.

[http://dx.doi.org/10.1007/s11205-008-9346-0]

[45] Fordyce MW. A review of results on the happiness measures: A 60-second index of happiness and mental health. Soc Indic Res 1988; 20: 355-8. [http://dx.doi.org/10.1007/BF00302333]

[46] Merkas M, Brajsa-Zganec A. Children with different levels of hope: are there differences in their selfesteem, life satisfaction, social support, and family cohesion? Child Indic Res 2011; 4: 499-514. [http://dx.doi.org/10.1007/s12187-011-9105-7]

[47] Mlacic B, Milas G, Kratohvil A. Adolescent personality and self-esteem -An analysis of self-reports and parental-ratings. Drust Istraz 2007; 16(87-88): 213-36.

[48] Pokrajac-Bulian A, Zivcic-Becirevic I. Locus of control and self-esteem as correlates of body dissatisfaction in croatian university students Eur Eat Disord Rev 2004; 12: 1-7.

[49] Brajsa-Zganec A. The long-term effects of war experiences on childrens depression in the Republic of Croatia. Child Abuse Negl 2005; 29(1): $31-43$. [http://dx.doi.org/10.1016/j.chiabu.2004.07.007] [PMID: 15664424]

[50] Myers R. Classical and modern regression with applications. 2nd ed. Boston, MA: Duxbury 1990.

[51] Pilarov barometer 2015. [Retrieved 2016 Oct 29]. Available from: http://barometar.pilar.hr/en/

[52] Brajsa-Zganec A, Kaliterna Lipovcan Lj. Quality of life, life satisfaction and happiness in professional care givers. Drus Istraz 2006; 15(84-85): 713-28.

[53] Bar-On R, Brown JM, Kirkcaldy BD, Thome EP. Emotional expression and implications for occupational stress; an application of the Emotional Quotient Inventory (EQ-i). Pers Individ Dif 2000; 28: 1107-18. [http://dx.doi.org/10.1016/S0191-8869(99)00160-9]

[54] Lipovcan LK, Brkljacić T, Sakić V. Monthly income and subjective well-being of Croatian citizens. Croat Med J 2007; $48(5)$ : 727-33. [PMID: 17948959]

[55] Kaliterna Lipovcan LJ, Burušić J. Age and Gender Differences in Well-being in Croatia. In: Eckermann E, Ed. Gender, Lifespan and Quality of Life: An International Perspective. Dordrecht, NL: Springer 2014; pp. 199-219. [http://dx.doi.org/10.1007/978-94-007-7829-0_15]

[56] Diener E, Ng W, Harter J, Arora R. Wealth and happiness across the world: material prosperity predicts life evaluation, whereas psychosocial prosperity predicts positive feeling. J Pers Soc Psychol 2010; 99(1): 52-61. 
[http://dx.doi.org/10.1037/a0018066] [PMID: 20565185]

[57] Diener E, Tay L, Oishi S. Rising income and the subjective well-being of nations. J Pers Soc Psychol 2013; 104(2): 267-76. [http://dx.doi.org/10.1037/a0030487] [PMID: 23106249]

[58] Eurofound Trends in quality of life - Croatia: 2007-2012. Luxembourg: Publication Office of the European Union 2014.

[59] Robinson MD. The reactive and prospective functions of mood: Its role in linking daily experiences and cognitive well-being. Cogn Emotion 2000; 14(2): 145-76.

[http://dx.doi.org/10.1080/026999300378914]

[60] Parkinson B, Totterdell P. Deliberate affect-regulation strategies: Preliminary data concerning reported effectiveness and frequency of use. In: Frijda NH, Ed. Proceedings of the Ninth Meeting of the International Society for Research on Emotions. Storrs: 1086 CT: ISRE 1996; pp. 401-5.

[61] Larsen RJ, Prizmic Z. Regulation of emotional well-being: Overcoming the hedonic treadmill. In: Larsen ME, Ed. The science of subjective well-being. New York, NY, US: Guilford Press 2008; pp. 258-89.

[62] Cohn MA, Fredrickson BL, Brown SL, Mikels JA, Conway AM. Happiness unpacked: positive emotions increase life satisfaction by building resilience. Emotion 2009; 9(3): 361-8. [http://dx.doi.org/10.1037/a0015952] [PMID: 19485613]

[63] Moskowitz JT, Shmueli-Blumberg D, Acree M, Folkman S. Positive affect in the midst of distress: Implications for role functioning. J Community Appl Soc Psychol 2012; 22(6): 502-18. [http://dx.doi.org/10.1002/casp.1133] [PMID: 23175617]

[64] Diener E. Subjective well-being. The science of happiness and a proposal for a national index. Am Psychol 2000; 55(1): 34-43. [http://dx.doi.org/10.1037/0003-066X.55.1.34] [PMID: 11392863]

[65] Huppert FA. Psychological well-being: Evidence regarding its causes and consequences. Appl Psychol Health Well-Being 2009; 1(2): 137-64. [http://dx.doi.org/10.1111/j.1758-0854.2009.01008.x]

[66] Meng R, Luo Y, Liu B, Hu Y, Yu C. The Nurses Well-Being Index and Factors Influencing This Index among Nurses in Central China: A Cross-Sectional Study. PLoS One 2015; 10(12): e0144414. [http://dx.doi.org/10.1371/journal.pone.0144414] [PMID: 26680594]

[67] Dziegielewski S, Turnage B, Roest-Marti S. Addressing stress with social work students: a controlled evaluation. J Soc Work Educ 2004; 40(1): 105-19.

[68] Polson M, Nida R. Program and trainee lifestyle stress: a survey of AAMFT student members. J Marital Fam Ther 1998; $24(1)$ : 95-112. [http://dx.doi.org/10.1111/j.1752-0606.1998.tb01065.x] [PMID: 9474526]

[69] Hirsch BJ, Engel-Levy DL, Bois D, Hardesty PH. The role of social environments in social support. In: Sarason BR, Sarason IG, Pierce GR, Eds. Social support: An international view. New York: Wiley 1990; pp. 367-93.

[70] Lyubomirsky S, Layous K. How do simple positive activities increase well-being? Curr Dir Psychol Sci $2013 ; 22(1)$ : 57-62. [http://dx.doi.org/10.1177/0963721412469809]

[71] Diener E, Emmons RA, Larsen RJ, Griffin S. The Satisfaction With Life Scale. J Pers Assess 1985; 49(1): 71-5. [http://dx.doi.org/10.1207/s15327752jpa4901_13] [PMID: 16367493]

[72] Watson D, Clark LA, Tellegen A. Development and validation of brief measures of positive and negative affect: the PANAS scales. J Pers Soc Psychol 1988; 54(6): 1063-70. [http://dx.doi.org/10.1037/0022-3514.54.6.1063] [PMID: 3397865]

[73] Cheung F, Lucas RE. Assessing the validity of single-item life satisfaction measures: results from three large samples. Qual Life Res 2014; 23(10): 2809-18.

[http://dx.doi.org/10.1007/s11136-014-0726-4] [PMID: 24890827]

[74] Jovanović V. The validity of the Satisfaction with Life Scale in adolescents and a comparison with single-item life satisfaction measures: a preliminary study. Qual Life Res 2016; 25(12): 3173-80.

[http://dx.doi.org/10.1007/s11136-016-1331-5] [PMID: 27262574]

(C) 2017 Brajsa-Zganec et al.

This is an open access article distributed under the terms of the Creative Commons Attribution 4.0 International Public License (CC-BY 4.0), a copy of which is available at: https://creativecommons.org/licenses/by/4.0/legalcode. This license permits unrestricted use, distribution, and reproduction in any medium, provided the original author and source are credited. 